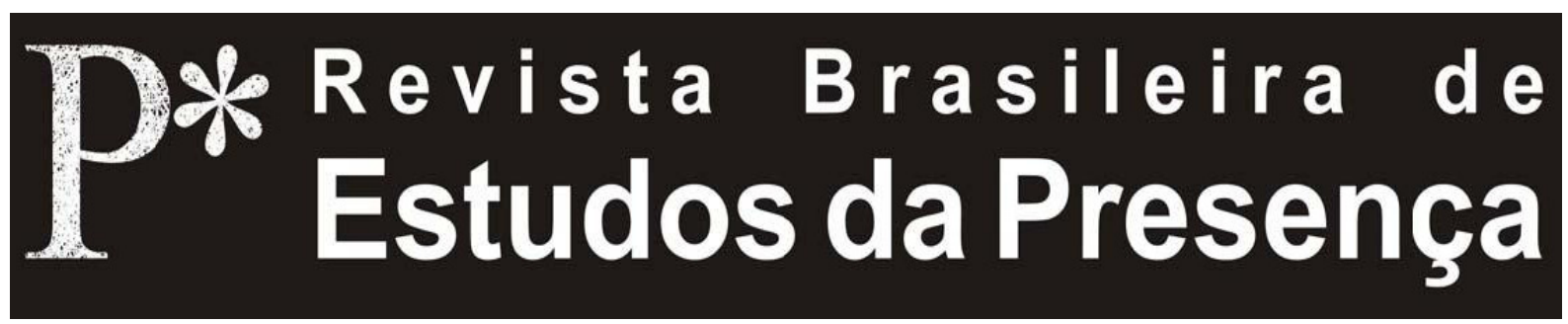

DOI - http://dx.doi.org/10.1590/2237-266030156

ISSN 2237-2660

\title{
As Contribuições da Pedagogia de François Delsarte para o Ensino da Dança Moderna
}

Marcilio de Souza Vieira Universidade Federal do Rio Grande do Norte - UFRN, Natal, RN, Brasil

RESUMO - As Contribuições da Pedagogia de François Delsarte para o Ensino da Dança Moderna - O presente texto apresenta algumas contribuições da pedagogia de Delsarte para a dança moderna. Revolucionário do movimento e do gesto para as artes cênicas, o delsartismo contribuiu significativamente para a emancipação da dança na América e na Europa. Mesmo não tendo criado um sistema especificamente para a dança, este foi difundido por seus discípulos e influenciou uma geração de dançarinos modernos. Este texto objetiva refletir a influência da pedagogia de François Delsarte para a dança, bem como contribuir para um pensamento de dança (moderna) renovador. A abordagem metodológica utilizada para a reflexão do tema proposto parte da análise de conteúdo.

Palavras-chave: Dança. Delsarte. Pedagogia. Corpo. Movimento.

ABSTRACT - The Contributions of François Delsarte's Pedagogy Modern Dance Training - This paper presents some of the contributions of Delsarte's pedagogy to modern dance. Delsatism started a revolution in movement and gestures in the performing arts, which has significantly contributed to the emancipation of dance in America and Europe. Although he did not create a system specifically for dance, it was disseminated by his students, influencing a whole generation of modern dancers. This article reflects on the influence of François Delsarte's pedagogy on dance, and aims at contributing to a new and refreshing ideas in the field of (modern) dance. The methodological approach used in this discussion is based on content analysis.

Keywords: Dance. Delsarte. Pedagogy. Body. Movement.

RÉSUMÉ - Les Contributions de la Pédagogie de François Delsarte pour l'Enseignement de la Danse Moderne - Ce texte présente quelques contributions de la pédagogie de Delsarte pour la danse moderne. Révolutionnaire du mouvement et du geste pour les arts de la scène, le delsartisme a largement contribué à l'émancipation de la danse en Amérique et en Europe. Bien qu'il n'ait pas conçu un système spécialement dédié à la danse, ce dernier a été diffusé par ses disciples et a influencé toute une génération de danseurs modernes. Cet article cherche non seulement à souligner l'influence de la pédagogie de François Delsarte pour la danse mais aussi à contribuer au renouvellement de la pensée sur la danse (moderne). L'approche méthodologique sur laquelle s'appuie la réflexion est celle de l'analyse de contenu. Mots-clés: La Danse. Delsarte. Pédagogie. Corps. Mouvement. 
Considerado o descobridor dos princípios fundamentais da dança moderna François Delsarte contribuiu significativamente para a emancipação dessa dança na América e na Europa. Mesmo não tendo criado um sistema especificamente para a dança, este foi difundido por seus discípulos e influenciou uma geração de dançarinos modernos numa sociedade que passava por profundas transformações sociais e políticas, ocorridas no início do século XX no mundo (as duas Grandes Guerras Mundiais, a crise de 1929, o Comunismo, o Nazismo etc.).

Sua obra influenciou toda uma geração de artistas destinados a reinventar as bases da linguagem da dança moderna, do gesto e do movimento, o que contribuiu para uma nova tradição teatral; a tradição expressiva do século XX, substituindo a tradição representativa do século XIX e estabelecendo um conjunto de preceitos ensinados em seu curso de estética aplicada.

Revolucionário do movimento e do gesto para as artes cênica, Delsarte diz que a qualidade gestual é alterada profundamente quando as diferentes regiões corporais se combinam. $\mathrm{O}$ esteta criou uma variedade de movimentos gestuais que foram utilizadas por atores e bailarinos nas primeiras décadas do século XX e que muito influenciou outros estudiosos, a exemplo de Dalcroze. Delsarte em seus estudos não mediu esforços para encontrar uma análise precisa para a expressão.

Este texto objetiva refletir a influência da pedagogia de François Delsarte para a dança moderna, bem como contribuir para um pensamento de dança renovador. A abordagem metodológica utilizada para a reflexão do tema proposto parte da análise de conteúdo (Bardin, 2004), que se baseia na dedução aplicada ao discurso dos sujeitos observados. Em nossa análise, esse discurso é encontrado na contribuição da pedagogia delsartiana para a dança moderna.

\section{Notas Esparsas sobre a Pedagogia de François Delsarte}

Eu trago para a vossa apreciação um objeto que é o mais elevado de todas as ciências. Ele é mais belo que as esculturas de Phidias. Ele encerra mais harmonia do que todas as obras de Beethoven, de Mozart e mais poesia 
do que já foi revelada pelos maiores poetas do mundo. Enfim, todas as concepções reunidas do gênio humano desaparecem como sombras diante desta obra suprema. Trata-se, caros senhores, da obra-prima de Deus, tratase de vós mesmos! Trata-se daquilo que o homem mais ignora no mundo, quer dizer, o homem (conforme conferência proferida por Delsarte à Escola Real de Medicina em 1867 apud Porte, 1992, p. 233).

Delsarte foi um virtuose e durante toda sua carreira artística recebeu diversos prêmios. François Delsarte (18111871) nasceu em Solesmes, em um pequeno vilarejo ao norte da França. Seguiu, com a idade de 14 anos, para a capital, onde pôde aprofundar seus estudos de canto na Escola Real de Música e Declamação de Paris. Devido a uma condução irresponsável de seu talento, o jovem virtuose foi obrigado a encerrar prematuramente uma carreira inquestionavelmente brilhante, uma vez que teve sua voz, instrumento primeiro de seu trabalho, completamente danificada; desde então, dedicouse à fundamentação de um pensamento sobre a expressividade do corpo, revelada pela tríade voz-palavra-gesto (emoçãopensamento-vontade).

Os problemas de afonia que o fizeram parar de cantar e que, para ele, foram fruto de inadequado direcionamento técnico-pedagógico, aliados à percepção de que a forma de interpretação que estudou tinha características estilizadas e falsas, parecem ter sido suas primeiras motivações a estudar a expressividade do ser humano, interessando-se por entender o gesto e suas relações com o funcionamento biomecânico e emocional do corpo humano (Madureira, 2002; Soares; Madureira, 2005).

Delsarte desenvolveu pesquisa rigorosa sobre expressão corporal, buscando entender como se exprimiam os sentimentos humanos e como a gestualidade corporal se organizava e se relacionava com as emoções.

Para tal, dirigiu sua atenção para o movimento cotidiano das pessoas em praças, hospitais, na rua; observou a expressividade do corpo na arte (em atuação no teatro, expresso em pinturas e esculturas), também estudando e participando de aulas de anatomia. Seu interesse parece ter sido descobrir uma forma de trazer a naturalidade e 
a apropriação do modo de expressar cotidiano para a expressividade cênica, nas suas múltiplas formas (Santos, 2011, p. 182).

Sua preocupação parece ter sido, realmente, a busca pela mais perfeita expressividade do corpo e a elaboração de um sistema que colaborasse com todas as áreas para as quais o gestual, a posição corporal, a entonação da voz fossem importantes. "Era esta a sua lógica de arte: comover, persuadir e convencer, através do triplo aparato orgânico: voz-palavragesto; expressos a partir da natureza tríplice do homem: vidaalma-espírito" (Madureira, 2002, p. 18).

O esteta não observou o corpo espetacular, ao contrário, elegeu o corpo ordinário como centro de suas reflexões poético filosóficas. Observou os corpos que vagavam ordenados pelas ruas de Paris. Ele observou também os corpos moribundos nos leitos hospitalares, as crianças brincando nos parques, os operários-máquina nas fábricas, os gestos que compunham salões burgueses e festas populares. Observou, enfim, corpos fabricados por uma sociedade recém-inaugurada, naufragados na economia e inexpressividade de um corpo morto (Madureira, 2002). Como resultado de todo esse material recolhido através de anotações e desenhos, Delsarte chegou à formulação de seu sistema.

Em suas observações sobre o corpo Delsarte se dedicou na compreensão do gesto para fabricar a expressão.

A gesticulação do corpo é um poder de expressão natural que abre para a significação existencial. Assim, os gestos são compreendidos pela reciprocidade intersubjetiva, pois quando duas significações percebidas se entrelaçam, um novo mundo cultural começa a existir. Há um novo sentido, uma variação do ser-no-mundo dado pela diferenciação da mímica, do gesto. Assim, o sentido se faz para cada um no contato corpóreo de sua existência. É num mundo sensível, então, que a fala se revela como saber intersubjetivo, um meio de expressão no nível do corpo que antecede o juízo.

É alhures, porém, que Merleau-Ponty (1999) discutirá a relação entre gesto e expressividade ao dizer que a fala é uma modalidade de gesto, o que nos obriga a reavaliar tanto o 
que entendemos por fala quanto o que entendemos por gesto. $\mathrm{O}$ autor referenciado classifica as operações de fala em dois tipos: a falada e a falante. A primeira corresponde à fala que apenas utiliza os sentidos já criados e estereotipados, remete à linguagem em estado nascente, como um ato instituinte $\mathrm{e}$ criativo, isto é, aquele momento em que ainda não se sabe exatamente o que vai ser comunicado, mas já existe um querer dizer; a segunda, ao contrário, caracteriza-se por ser uma atividade expressiva, que não só renova, mas inaugura sentido, é remetida à linguagem sedimentada constituída por significações correntes e demais formas de expressão de um dado meio sociocultural, ou seja, é a base da comunicação social, porque é o próprio saber sedimentado na linguagem.

Para Merleau-Ponty (1999) a palavra tem sentido próprio e recorrerá ao gesto para esclarecer a comunicação pela palavra, buscando no corpo o entendimento para essa compreensão. A fala emerge enquanto gesto de um corpo que é todo relação de sentido com o mundo. Para o autor, o modo de apreensão do sentido da fala do outro é o mesmo que o do gesto corporal: eu os compreendo na medida em que os assumo como podendo fazer parte do meu próprio comportamento. Dessa forma, a palavra se faz gesto na relação com a linguagem, o repertório gestual, as ambiguidades e com a expressão corporal.

Todo o meu aparelho corporal se reúne para alcançar e dizer a palavra, assim como minha mão se mobiliza espontaneamente para pegar o que me estendem [...]. O "eu" que fala está instalado em seu corpo e em sua linguagem não como numa prisão, mas, ao contrário, como um aparelho que o transporta magicamente à perspectiva do outro (Merleau-Ponty, 2002, p. 41).

Os gestos enfatizam, descrevem, completam; às vezes traem o conteúdo de um discurso oral. Estão sempre presentes na performance do intérprete. "O gesto não transcreve nada, mas produz figurativamente as mensagens do corpo. A gestualidade assim se define (assim como a enunciação) em termos de distância, de tensão, de modelização, mais do que como sistema de signos" (Zumthor, 2010, p. 206).

O gesto, na dança moderna, é o comentarista da palavra, é a revelação do pensamento da dança. Ele é poético, pois o 
bailarino-dançarino dança consigo, dança com o outro, faz sua dança, incorpora gestualidades do cotidiano, de seu mundo vivido, gestualidades que são incorporadas em suas vivências quando dança.

Os gestos se revelam num poder persuasivo, colocando em jogo todos os sentidos, não só de quem executa, mas também de quem observa. Merleau-Ponty (1999) afirma que o corpo é o nosso meio geral de ter o mundo. Para o filósofo, esse corpo, quando se movimenta, reorganiza-se, informa-se sobre o meio ambiente, ao mesmo tempo informa-se sobre si mesmo, criando significações transcendentes ao dispositivo anatômico. Desse modo, o autor citado argumenta que:

Ora ele se limita aos gestos necessários à conservação da vida e correlativamente, põe em torno de nós um mundo biológico; ora, brincando com seus primeiros gestos e passando de seu sentido próprio a um sentido figurado, ele manifesta através dele um novo núcleo de significação: é o caso dos hábitos motores como a dança. Ora, enfim, a significação visada não pode ser alcançada pelos meios naturais do corpo; é preciso então que ele se construa um instrumento, e ele projeta em torno de si um mundo cultural (Merleau-Ponty, 1999, p. 203).

Na dança moderna, o gesto é singular a cada bailarinodançarino; esses gestos criam sentidos de significações, logo, ao criarem sentidos, eles admitem verdades ou uma verdade. "Uma verdade que não se assemelhe às coisas, que não tenha modelo exterior nem instrumentos de expressão predestinados, e que seja, contudo verdade" (Merleau-Ponty, 1999, p. 59). O referido autor argumenta que,

É por meu corpo que compreendo o outro, assim como é por meu corpo que percebo coisas. Assim compreendido, o sentido do gesto não está atrás dele, ele se confunde com a estrutura do mundo que o gesto desenha e que por minha conta eu retomo, ele se expõe no próprio gesto (Merleau-Ponty, 1999, p. 253).

Os gestos fazem parte dos meios usados para o ser humano se comunicar; contribuem para dar forma e codificar as relações sociais entre os indivíduos e entre os grupos. Schmitt 
(2006) afirma serem os gestos constituintes de uma realidade social e que dependem da história social. São o meio pelo qual o corpo estabelece relações simbólicas enquanto apreensão individual, interpessoal e de movimento.

[...] eles contribuem para construir o quadro onde os códigos sociais são propostos ou contestados; os gestos são ainda objectos dos juízos de valor, das distinções sociais e de todas as prescrições e condenações que os acompanham e confrontam, que se trate de gestos de pudor [...], gestos de amor [...] gestos que correspondam ao papel social que se espera de cada um (Schmitt, 2006, p. 22).

A historicidade do corpo faz com que haja modificações, e nossos gestos adquiram significados novos mediante as experiências que vão ocorrendo. É através desses gestos que somos capazes de expressar muitos desses símbolos e esconder outros, formando, portanto, a linguagem do corpo que está sempre se reorganizando. E por possuir espacialidade e temporalidade próprias, cada corpo vai adquirindo percepções de acordo com o mundo que lhe é específico.

Os gestos são um dos elementos constitutivos dos rituais e das danças da tradição. "Esses gestos são 'movimentos' do corpo [...]; são acções (actus) na medida em que visam um fim prático ou simbólico" (Schmitt, 2006, p. 24).

Na dança moderna, a amplitude, o ritmo, a velocidade desses movimentos e dessas ações gestuais têm a maior importância: um gesto pode ser apressado, mas também pode ser, dependendo das circunstâncias, lento, comedido, exacerbado ou mesmo condensar-se à realidade a que se adequa o bailarino-dançarino. Na dança moderna toda gestualidade é elemento de grande impacto na transmissão e recepção da performance do intérprete. Nesta, os movimentos acompanham a narração da cena e, como justifica Zumthor (2010, p. 207), "[...] cabe ao corpo modalizar o discurso, explicar seu intento. $\mathrm{O}$ gesto gera no espaço a forma externa do poema. Ele funda sua unidade temporal, escandindo-a de suas recorrências".

Madureira (2002) informa que, para Delsarte, o controle do gesto não estaria voltado simplesmente à educação e à moral do corpo, mas, sobretudo, à concepção de um ator ideal e que 
se fazia necessário que este entrasse em contato com as leis que regem a expressão, imprimi-las em seu corpo para que o texto, a canção, a coreografia ocorressem independente do pensamento ou da vontade do executante.

A verdade é que o sistema de Delsarte não tem nada de misterioso. Ele tem a simplicidade de uma ciência. A prática pode ser, certamente, rigorosa e delicada, uma realidade que pode não ser conveniente aos diletantes, que desejam a cena como simples ocasião de exibição preguiçosa de suas preciosas e pequenas personalidades. Delsarte busca algo mais elevado e mais importante que a simples apresentação pública de uma individualidade encenada. Ele procura transformar um ator num artista, ele procura tornar o ator capaz de abdicar-se de sua própria personalidade, para que ele possa assumir o mais fielmente possível os diversos personagens e papeis. Os meios para atingir este fim, tantas vezes negligenciados, mas que desejamos ardentemente, são evidentes, e tendem a resultados tangíveis. Ensinamos o aluno a expressar uma paixão segundo as leis daquela paixão. O gesto adequado, a atitude adequada, a expressão adequada da face, enfim, a representação física forte e precisa de um pensamento sobre a paixão: medo, raiva, desejo... Esta é a contribuição de Delsarte, e muito mais! Ele nos ensina como conquistar a individualidade durante a expressão da emoção, e acrescenta: pegue este sistema de exercícios estéticos e aplique-os aos movimentos de todas as partes do seu instrumento (quer dizer todo o seu corpo). Bom, as leis da expressão tornar-se-ão, progressivamente, penetrando, pouco a pouco, sua natureza vital e assim se tornando uma manifestação da emoção, científica e absolutamente precisa, tornando-se espontânea (Mackaey in Porte Apud Madureira, 2002, p. 183).

Delsarte, observador do movimento humano, criou um sistema capaz de revolucionar a história do gesto. Por meio de observações de si próprio e de outras pessoas estabeleceu uma lista de gestos que correspondeu a estados emocionais precisos.

Para ele, nenhum gesto deve existir e muito menos ser apresentado sem significado. Convencer, comover, persuadir através do triplo aparato voz-palavra-gesto expressos a partir da natureza tríplice do ser humano vida-espírito-alma foram sua lógica da arte. 
Essa tríade respeita a uma tríplice possibilidade, a saber: excêntrica, ligada a porção da vida e mais voltada para fora; normal, que faz ligação com a alma, sendo a mais equilibrada, e concêntrica, que faz menção a porção do espírito e é mais voltada para dentro do ser.

Para um maior entendimento dessa tríplice possibilidade, Madureira (2002, p. 61) exemplifica a aplicação desta tríade, proposta por Delsarte, no movimento das mãos:

Existe um centro nas coisas, nos gestos, nos movimentos, e duas forças que se deslocam para fora (do centro) ou para dentro. As mãos, por exemplo, relaxadas em estado de normalidade, representam a qualidade gestual NORMAL. Mãos abertas, estendidas, indicam uma gestualidade EXCÊNTRICA. Por fim, se as mãos estiverem fechadas, contraídas, serão enquadradas como uma gestualidade CONCÊNTRICA.

Ao fazer um estudo minucioso do corpo, em suas principais posições expressivas, ele criou sequências a partir de paralelismos, oposições e sucessões muito utilizadas por atores e de grande interesse dos bailarinos modernos.

Foi imerso nesses estudos e conclusões que Delsarte afirmou:

O gesto é mais que o discurso. Não é o que dizemos que convence, mas a maneira de dizer. O gesto é o agente do coração, o agente persuasivo. Cem páginas, talvez, não possam dizer o que um só gesto pode exprimir, porque num simples movimento, nosso ser total vem à tona, enquanto que a linguagem é analítica e sucessiva (Delsarte apud Azevedo, 2009, p. 54).

Delsarte observou, controlou, descreveu o gesto para fabricar a expressão. Este controle do gesto não estaria voltado simplesmente à educação e à moral do corpo, mas, sobretudo à concepção de um ator ideal, treinado para ser um fiel Instrumento da alma (Madureira, 2002).

\section{O que a Dança tem a Dizer a François Delsarte?}

Tomada como um exercício da moral, a dança vista através do olhar de Delsarte pode ser lida como um programa 
político-corporal ou como uma ascese. Os ensinamentos de seu sistema, transmitidos à dança não por Delsarte, que morreu em 1871, mas por seus discípulos, acabaram por influenciar mesmo que indiretamente a dança moderna na América (Isadora Duncan, Ruth Saint-Denis/Ted Shawn, Doris Humphrey e Martha Graham) e a dança moderna europeia, mais especificamente na Alemanha, desenvolvendo-se na chamada dança expressiva e posteriormente no teatro-dança.

Ao determos nosso olhar para tal sistema e sua influência para a dança não podemos nos esquecer de um dos discípulos de Delsarte: Geneviéve Stebbins (1857-1915), professora de Dança e educadora feminina que integrou o delsartismo à sua prática, sistematizando e publicando estudos que demonstram essa ligação. Seu nome merece ser destacado, uma vez que influenciou Loie Füller, Isadora Duncan e Ruth Saint-Denis, as três principais figuras da Nova Dança do início do século $\mathrm{XX}$, que fomentaram discussões acerca dos princípios técnicoexpressivos do corpo.

Duncan e Saint-Denis se formaram no método do delsartismo influenciadas por suas mães; a primeira retirou do sistema a fé profunda na unidade corpo-alma e na mitificação da plástica grega e a segunda, treinada numa ginástica harmônica, formou as bases de suas primeiras danças. Mas foi pelas mãos de Ted Shawn que a releitura do delsartismo para a dança foi aplicada na Denishawnschool e influenciou toda uma geração de dançarinos modernos (Ropa, 1990).

A incidência do delsartismo nas propostas de dança de Denis e Shawn também pode ser apontada na organização da Denishawnschool: a linha adotada objetivava oferecer uma formação que ultrapassasse o quadro da preparação corporal para atingir o conjunto da personalidade, inclusive inteligência e sensibilidade do aluno. Além disso, a dramaturgia da Dança criada por Saint Denis explora o uso de paradas e chama a atenção para poses significantes, um trabalho que valoriza a definição gestual como importante elemento de construção cênica (Santos, 2011, p. 187).

Na Europa, o sistema de Delsarte foi difundido por seus discípulos que se estabeleceram em escolas de rítmica femi- 
nina e ginástica. Na Alemanha, Laban estudou os princípios do sistema delsartismo e os transformou em técnica de dança.

Os ensinamentos de Delsarte foram relidos por outras artes como a dança por exemplo, mas ele não imaginava que tal sistema ou método fosse aplicado à dança que considerava desprezível por razões morais e culturais (Ropa, 1990).

\section{Contribuições de uma Pedagogia para a Dança Moderna por um Precursor não Reconhecido}

Perguntamo-nos: como os ensinamentos do sistema delsartismo pôde ser aplicado à dança moderna para mudar seu significado e sua linguagem?

Lembramos que Delsarte nunca se interessou pela dança, no entanto seus ensinamentos chegaram a esta por meio de seus discípulos Steele MacKaye, Genéviève Stebbins e Henriette Crane. Ele observou como se exprimem os sentimentos na vida real e formulou dois grandes princípios, a Lei da Correspondência e a Lei da Trindade, que foram utilizados na dança moderna e contribuíram imensamente para liberar o corpo dos gestos codificados do ballet para uma dança de expressão e ação.

O primeiro princípio diz respeito a toda função do espírito que corresponde a uma função do corpo e a toda grande função do corpo que corresponde a um ato espiritual e o segundo princípio parte do reconhecimento de que as três dimensões do homem - a vida, a alma e o espírito - formam uma unidade.

São consequências imediatas de suas ideias para a dança a partir dos princípios da correspondência e da trindade: o primado do tronco como centro propulsor da expressão, que se obtém pela contração e pelo relaxamento dos músculos; o papel das sucessões que partem do tronco e percorrem todo o corpo; o uso controlado e rítmico, consciente e voluntário da alternância entre tensão e extensão e a relação do corpo com o chão cujo contato vitalizante com os pés descalços dá ao bailarino toda sua densidade terrestre, carnal e humana (Garaudy, 1980; Bourcier, 1987). 
Estas ideias não poderiam ter sido concebidas como prática de uma expressão estética corporal sem o apoio de uma teoria e prática determinante da história dos costumes daquela época. Nos referimos a elaboração americana dos ensinamentos de François Delsarte (1811-1871). A gigantesca teoria da expressão humana arduamente elaborada em Paris entre os anos de 1830 e 1870, desenvolvida pelo mestre de canto, recitação e oratória François Delsarte é, talvez, o fio condutor mais tenaz que conduz o pensamento e a experiência dos protagonistas da nova dança, na América e na Europa (Ropa, 1990 apud Madureira, 2002, p. 173).

Delsarte distinguiu ainda três formas essenciais de movimentos muito utilizados na dança moderna: os movimentos de oposições, os paralelismos e as sucessões.

Os movimentos de oposição são aqueles nos quais duas partes do corpo se movem ao mesmo tempo em sentidos opostos; os paralelismos quando duas partes do corpo se movem ao mesmo tempo e na mesma direção e as sucessões são movimentos que percorrem o corpo todo. Garaudy (1980) argumenta que o uso consciente dos movimentos de sucessão foi um dos princípios mais importantes nos quais se baseou a dança moderna para renovar a técnica de dança.

Podemos encontrar tais princípios influenciando as técnicas de dança de Graham e Humphrey: no caso de Graham, a técnica do tension - release (tensão e relaxamento), em Humphrey, sua técnica de fall - recovery (queda e recuperação). Ambas apostaram no princípio da correspondência para o desenvolvimento de suas técnicas.

O sistema de Delsarte influenciou também artistas europeus que se interessaram pelo seu sistema. Bourcier (1987, p. 247) argumenta que:

O delsartismo teve, portanto, uma influência estabelecida historicamente na dança moderna dos Estados Unidos. Atinge também a Alemanha. Isadora Duncan importou-o, depois de sua primeira turnê a Berlim em 1902, e desenvolveu seu ensino na escola que fundou em seguida em Grünewald. Por sua vez, Rudolf Von Laban integrou em seu próprio sistema de ensino vários princípios delsartianos. 
Dentre os artistas europeus que estudaram o delsartismo destaca-se Laban, que estudou com alunos de Delsarte, e que, como ele, debruçou-se de forma minuciosa sobre seu objeto de estudo: o movimento, suas qualidades e dinâmicas. Podemos citar como exemplo dessa relação direta com o sistema o conceito de esforço que se liga à noção de correspondência proposta pelo delsartismo.

Madureira (2002) afirma que há uma semelhança das leis delsartianas de movimento com as teorias espaciais de Laban; essa aproximação não é mera coincidência uma vez que Laban estudou o sistema de Delsarte com um de seus discípulos e certamente deve ter incorporado ao seu sistema de movimento aspectos da estética delsartiana.

Talvez a diferença entre os dois seja o enfoque dado ao corpo. Tomamos novamente a escrita de Madureira (2002, p. 151) para explicar: "Delsarte preocupava-se com a expressividade do gesto, enquanto Laban pensava no movimento".

Interessante observar que, de seu sistema, utilizado pelos dançarinos modernos e posteriormente por alguns contemporâneos infere-se que as oposições, os paralelismos e as sucessões apresentam-se como grandes ordens do movimento que, aliados às leis do movimento ou deslocamento, podese, a partir dos princípios da trindade e da correspondência, apresentar parâmetros para se pensar nessa dança a altura, a força, o movimento excêntrico/expansão-normal-concêntrico/ contração; sequência, direção, forma, velocidade, reação, extensão e balanço.

O quadro abaixo nos apresenta como o delsartismo influenciou uma geração de artistas das artes cênicas. Desta feita, sua teoria foi tomada, com maior ou menor rigor, por diversas áreas do conhecimento, como o teatro, a retórica, a ginástica e a dança. 


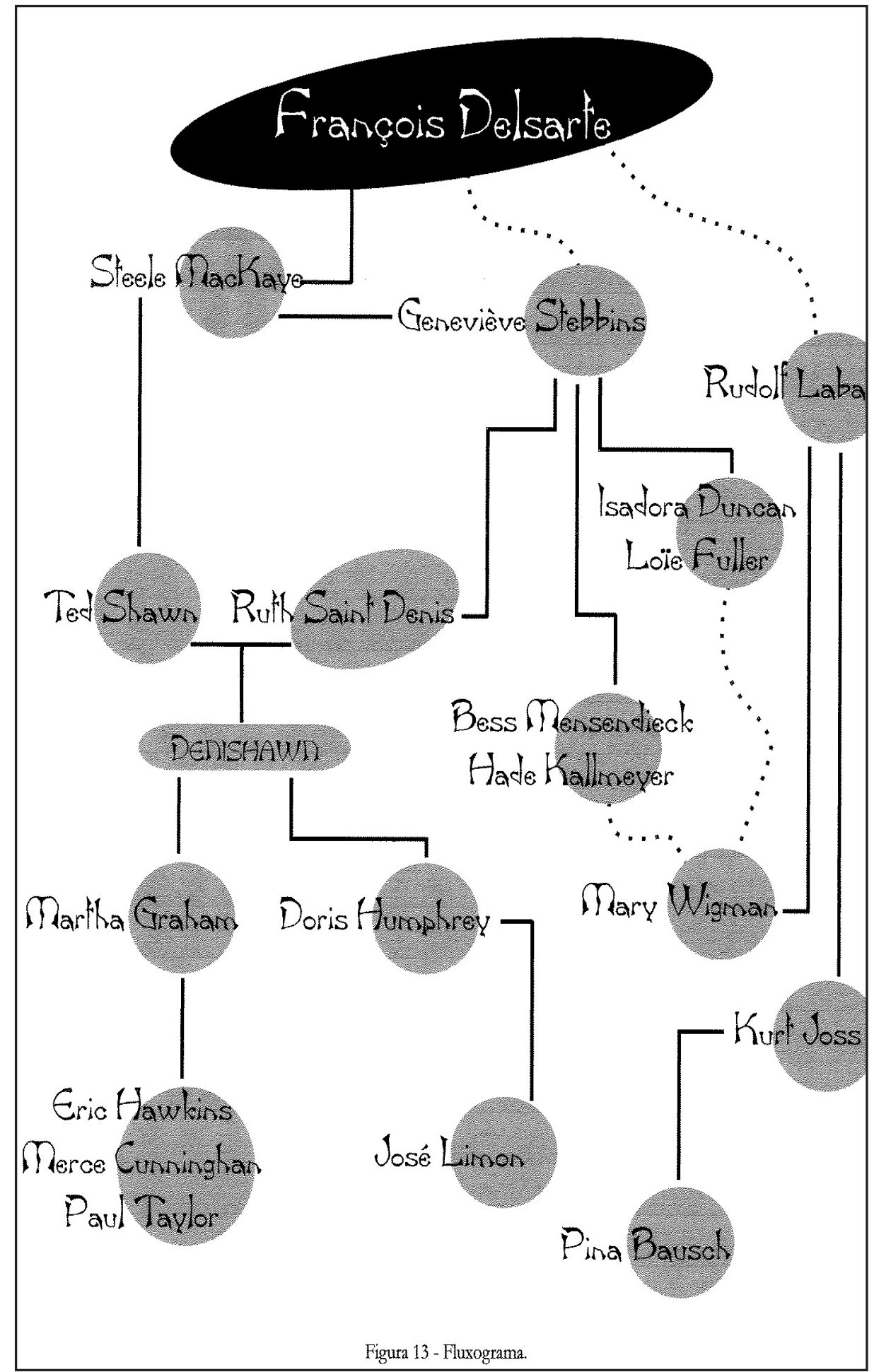

Quadro 1 - Fluxograma de Influência de François Delsarte.

Fonte: Madureira, 2002, p. 36. 
No fluxograma, extraído da dissertação de mestrado de Madureira (2002), observamos que o autor faz referência a diversas personalidades da dança moderna que foram influenciadas por Delsarte a partir de seus discípulos tais como Isadora Duncan, Loïe Fuller e Ruth Saint-Denis que foram iniciadas no delsartismo por Stebbins, Ted Shawn, aluno e parceiro de Saint-Denis, que recebeu influências de Henriette Crane.

$\mathrm{Na}$ Alemanha, os ensinamentos do delsartismo chegaram pelas apresentações de Duncan e Saint-Denis "[...] com trabalhos impregnados de uma nova e vital expressividade, um novo olhar sobre o corpo, fundamentado em princípios orgânicos de expressão" (Madureira, 2002, p. 31).

Ainda na Alemanha, Wigman e Laban foram influenciados por tal sistema e participaram ativamente do programa político-estético nazifascista que se utilizava do sistema delsartismo. Laban estudou os princípios da Estética Aplicada por um discípulo de Delsarte.

Parece claro afirmar que, os descendentes de Graham (Erick Hawkins, Merce Cunningham e Paul Taylor), Humphrey (Limón) e Jooss (Pina Bausch), no entanto, a título de esclarecimento do fluxograma apresentado, não foram influenciados diretamente pela obra de Delsarte. Dessa maneira não há uma hereditariedade estética desses coreógrafos da dança moderna com o esteta Delsarte.

\section{(in) Conclusões}

François Delsarte deixou para a arte um sistema que naquela época desvinculava-se de regras rígidas; ao ser acolhido pela dança tal sistema contribuiu com a arte do corpo em movimento. Esse corpo na dança, ora esculpido por técnicas rígidas do ballet, abre-se para novas aventuras da expressão com a dança moderna. Neste momento, a dança enquanto diversão, puro entretenimento, perde lugar para uma dança cada vez mais ligada à vida, aos conflitos e sentimentos humanos. Neste aspecto, "Delsarte é considerado o primeiro estudioso a definir princípios do movimento expressivo, fundamentais na dança moderna, catalogando os gestos que correspondem a estados emocionais" (Guinsburg, 2002, p. 299). 
Enfim, Delsarte contribuiu significativamente para a arte do corpo nas artes cênicas, não tanto como executor de obras, mas como transformador da percepção e das categorias utilizadas para pensar e realizar o trabalho artístico (Bonfitto, 2006).

Dessa forma, podemos inferir que a pedagogia de Delsarte e sua influência na dança possibilitou um redesenhar do movimento corporal para a dança moderna. Julgamos alguns pontos importantes a se destacar: o sistema delsartismo influenciou sobremaneira a dança moderna americana e europeia e contribuiu para se pensar o movimento nessa dança; os artistas/autores da dança moderna, influenciados pelo sistema de Delsarte, criaram seus métodos ou técnicas de ensino partindo-se da estética delsartiana e tal estética possibilitou uma reconfiguração do gesto, antes codificado pelo ballet, para uma nova géstica corporal descodificada e comprometida com um movimentar-se livre das amarras do ballet.

Convém ressaltar que a incidência do delsartismo nas propostas de dança pode ser observada nas técnicas das precursoras da dança moderna Fuller, Duncan e Saint-Denis e em seus predecessores Shawn, Graham e Humphrey.

Presume-se que seu sistema se fez presente na Europa, mais precisamente na Alemanha, contribuindo significativamente com a dança desenvolvida por Laban, influenciando ainda Jooss e Wigman.

Delsarte desenhou, mesmo não sabendo, uma redescoberta para a dança; uma dança livre das convenções do ballet, das marcas feitas nos corpos dos bailarinos. 


\section{Referências}

AZEVEDO, Sônia Maria de. O Papel do Corpo no Corpo do Ator. São Paulo: Perspectiva, 2009.

BARDIN, Laurence. Análise de Conteúdo. Tradução de Luis Antero Reto e Augusto Pinheiro. Lisboa, Portugal: Edições 70, 2004.

BONFITTO, Matteo. O Ator Compositor. São Paulo: Perspectiva, 2006.

BOURCIER, Paul. História da Dança no Ocidente. Tradução de Marina Appenzeller. São Paulo: Martins Fontes, 1987.

GARAUDY, Roger. Dançar a Vida. Tradução de Glória Mariani e Antônio Guimarães Filho. Rio de Janeiro: Nova Fronteira, 1980.

GUINSBURG, Jacob. O Expressionismo. São Paulo: Perspectiva, 2002.

MADUREIRA, José Rafael. François Delsarte: personagem de uma dança (re) descoberta. Dissertação. Campinas: Faculdade de Educação da Unicamp, 2002.

MERLEAU-PONTY, Maurice. Fenomenologia da Percepção. Tradução de Carlos Alberto Ribeiro de Moura. 2 ed. São Paulo: Martins Fontes, 1999.

MERLEAU-PONTY, Maurice. A Prosa do Mundo. Tradução de Paulo Neves. São Paulo: Cosac \& Naify, 2002.

PORTE, Alain. François Delsarte: une anthologie. Paris: IPMC, 1992.

RANDI, Elena (Org.). François Delsarte: le legge del teatro - Il pensiero scenicodel precursore della danza moderna. Roma: Bulzoni, 1993.

ROPA, Eugenia Casini (Org.). Alle Origine della Danza Moderna. Bolonha: Il Mulino, 1990.

SANTOS, Eleonora. François Delsarte, um Ponto para a Dança. Repertório, Salvador, n. 16, p. 181-190, 2011.

SCHMITT, Jean-Claude. O Corpo e o Gesto na Civilização Medieval. In: BUESCU, Ana Isabel; SOUSA, João Silva de; MIRANDA, Maria Adelaide de (Org.). O Corpo e o Gesto na Civilização Medieval. Lisboa: Edições Colibri, 2006. P. 22-36.

SOARES, Carmen Lúcia; MADUREIRA, José Rafael. Educação Física, Linguagem e Arte: possibilidades de um diálogo poético do corpo. Movimento, Porto Alegre, v. 11, n. 2, p. 75-88, maio/ago. 2005.

ZUMTHOR, Paul. Introdução à Poesia Oral. Tradução de Jerusa Pires Ferreira. São Paulo: Hucitec, 2010.

Marcilio de Souza Vieira é graduado em Artes Cênicas e Educação Física pela Universidade Federal do Rio Grande do Norte (UFRN), doutor em Educação pela mesma universidade. Professor Adjunto I do Departamento de Artes da UFRN.

E-mail: marciliov26@hotmail.com

Recebido em 26 de junho de 2012

Aprovado em 22 de julho de 2012 